Кравченко Людмила Владимировна

аспирант Российской академии народного хозяйства и государственной службы при Президенте РФ

\section{ДОГОВОР ПОТРЕБИТЕЛЬСКОГО КРЕДИТОВАНИЯ: УСТАНОВЛЕНИЕ ПРЕДЕЛОВ И ОГРАНИЧЕНИЙ ГРАЖДАНСКИХ ПРАВ СТОРОН}

\section{Аннотация}

Основные проблемы развития договорного права в современной России связаны с потребительским кредитованием, обеспечением сбалансированного соотношения общественных интересов, интересов кредиторов и заемщиков. В связи С этим особую роль приобретают исследования по установлению пределов и ограничений права на осуществление потребительского кредитования. В статье на основе опыта зарубежных стран и России анализируются правовые аспекты, касающиеся пределов и ограничений гражданских прав сторон потребительского кредитования. Сформулирован ряд принципов установления пределов и ограничений гражданских прав в договоре потребительского кредитования.

Ключевые слова:

договор, потребительское кредитование, гражданские права, пределы и ограничения, принципы, условия.
Kravchenko Lyudmila Vladimirovna

PhD student Russian Presidential Academy of National Economy and Public Administration

\section{CONSUMER LOAN AGREEMENT: ESTABLISHING LIMITS AND RESTRICTIONS OF CIVIL RIGHTS OF THE PARTIES}

Summary:

The main problems of the contract law development in modern Russia are linked to consumer lending and ensuring the balance between the public interests and the interests of creditors and borrowers. In this regard, the researches related to establishing limits and restrictions of civil rights on consumer lending assume the special role. Based on the experience of foreign countries and Russia the author analyzes the legal aspects concerning limits and restrictions of civil rights of consumer lending parties. The author formulates a number of principles for establishing limits and restrictions of civil rights in the consumer loan agreement.

Keywords: agreement, consumer lending, civil rights, limits and restrictions, principles, terms and conditions.

Согласно нормам Германского гражданского кодекса (§ 138 ГГК) все виды банковских вознаграждений должны отвечать требованиям, нарушение которых недопустимо. Суд устанавливает недействительность сделок, нарушающих общепринятые нормы морали и запрет ростовщичества. Урегулированный в Законе о потребительском кредите договор потребительского кредитования также включен в Германское гражданское уложение (§ 491 ГГУ).

В ФРГ основное условие в договоре о потребительском кредите (о процентах займа) подлежит контролю с точки зрения общепринятых норм морали и запрета ростовщичества. Именно на эти обстоятельства всегда обращает внимание Федеральный верховный суд ФРГ при проверке общих условий сделок согласно § 307 ГГК ФРГ.

Законодательство ФРГ прямо устанавливает, что «положения общих условий сделок недействительны, если вопреки требованиям доброй совести они ставят контрагента стороны, использующей общие условия, в чрезмерно невыгодное положение». Как показывает анализ гражданского законодательства ФРГ, подобное «чрезмерно невыгодное положение» может быть следствием того, что: положение общих условий сделок неясно и неоправданно; несовместимо с важными основами законодательного регулирования; настолько ограничивает существенные права или обязанности, вытекающие из природы договора, что ставит под угрозу достижение цели самого договора.

Согласно п. 3 § 307 ГГК ФРГ дополнительная ценовая оговорка подлежит контролю содержания, если она устанавливает отклоняющиеся от закона правила в отношении правовых предписаний [1, S. 209]. В то же время оговорки, которые устанавливают вознаграждение за дополнительное или вспомогательное исполнение, не подлежат контролю содержания со стороны Федерального верховного суда ФРГ.

В соответствии со сложившейся практикой Федерального верховного суда ФРГ недопустимо перекладывание на заемщика тех расходов, которые возникают при исполнении банком собственных обязательств или служат интересам банка [2, с. 72]. Так, например, согласно решению Федерального верховного суда ФРГ от 7 июня 2011 г. банк возлагает на потребителя недопустимое вознаграждение за действия, которые он совершает в ходе наблюдения за возвратом 
кредита, поскольку данная операция является чисто внутренней банковской деятельностью, служит лишь интересам банка.

Цель ограничений заключается в предотвращении случаев, когда потребитель, не имеющий соответствующего опыта, попадает в сложную экономическую ситуацию в результате принятия поспешных решений при заключении договора потребительского займа. В немецком законодательстве заемщику после заключения договора потребительского кредитования дается возможность еще раз обдумать договор займа, сравнить условия договора и цены. ГГУ содержит норму, согласно которой потребитель может отказаться от договора в течение двух недель (§ 495, 355 ГГУ). При этом банк обязан сообщить потребителю о данном праве (§ 355, абз. 2 ГГУ).

В России требования к договорам потребительского кредитования вытекают из норм Гражданского кодекса Российской Федерации (ГК РФ), федеральных законов «О защите прав потребителей», «О потребительском кредите (займе)» и др. Так, часть 2 ст. 5 Федерального закона о потребительском кредите от 21 декабря 2013 г. № 353-Ф3 (в редакции от 3 июля 2016 г.) относит к обязательным условиям договора потребительского кредита (займа) кроме условий, согласованных кредитором и заемщиком в соответствии с ч. 9 ст. 5 данного закона, нормы, закрепленные в ст. 428 ГК РФ. Часть 1 ст. 9 Федерального закона о потребительском кредите, обозначая, что процентная ставка по договору потребительского кредита (займа) может определяться с применением ставки в процентах годовых, не устанавливает пределов и ограничений данной ставки.

Несовершенство российского договорного права порождает случаи, когда потребительские кредиты достигают запредельной величины - 1000 \% годовых, что не соответствует нормам и принципам правового государства. Ученые-правоведы, общественные деятели, парламентарии сходятся в оценках, что подобные суммы процентов по договору потребительского займа не отвечают принципу добросовестности сторон кредитных отношений.

Установление пределов и ограничений является мерой, восстанавливающей права заемщиков как заведомо более слабой стороны потребительского займа. Верховный суд РФ отстаивает позицию, согласно которой условия договора потребительского кредитования не могут быть чрезмерно обременительными для заемщика.

Исследователи отмечают, что в договорах потребительского кредитования должны быть установлены пределы и ограничены суммы процентов займов [3]. Подобное ограничение должно распространяться на договоры как с физическими, так и с юридическими лицами: торгово-сервисными предприятиями, организациями (POS-кредиты) и др. Пределы и ограничения должны касаться целевых и нецелевых потребительских кредитов.

Условия договора потребительского кредитования должны позволять заемщикам четко представлять, на каких условиях они получают заем, как защищены их права, как ограничены штрафы и пени за невыполнение требований договора, каким образом они застрахованы от угроз долговой пирамиды. Особенно актуальны ограничения для кредитных организаций, занимающихся предоставлением экспресс-кредитов, различных форм pos-кредитования, решение о которых многие граждане нередко принимают поспешно, импульсивно.

Особое значение имеет включение в условия договора потребительского кредитования ограничений на сумму штрафов и пеней за невыполнение условий по потребительским кредитам. Ограничение прав сторон потребительского кредитования должно зависеть от того, насколько рискованной категории заемщиков выдаются потребительские кредиты, от размера кредита, срока его погашения, пеней за несвоевременный возврат.

Правовые ограничения потребительского кредитования являются элементами механизма правового регулирования, направленными на установление пределов (границ) дозволенного поведения кредиторов и заемщиков. Ограничения права на осуществление определенных действий в сфере потребительского кредитования необходимо рассматривать как прямо установленные законом правила, создающие препятствия для нарушения баланса интересов сторон потребительского кредитования.

Данные ограничения вызваны необходимостью соблюдения прав и законных интересов кредиторов и заемщиков, общества в целом. Их установление целесообразно только при наличии обоснованности соразмерности создаваемых препятствий в осуществлении субъективного гражданского права степени охраняемого этим ограничением законного интереса иных лиц [4, с. 27].

В сфрере потребительского кредитования ограничения права сторон могут быть классифицированы на обязательные (например, запрет со стороны государства на отдельные виды деятельности, включая предпринимательскую) и добровольные [5, с. 34].

Добровольные ограничения права в сфере потребительского кредитования возникают в том случае, когда банк по своей воле закрепил в учредительных документах добровольное ограничение своей правоспособности на основании п. 1 ст. 49 ГК РФ. Учредители кредитных организаций вправе установить самоограничения. Такое «самоограничение» правоспособности будет 
иметь силу и для третьих лиц, но лишь в том случае, когда они знали или должны были знать о нем (ст. 173 ГК РФ).

Следует отметить, что в России многие ограничения гражданских прав сторон потребительского кредитования вводятся актами публичного (административного), а не гражданского законодательства. Вместе с тем административный характер ограничений не обеспечивает должной защиты и гарантий имущественных прав граждан и юридических лиц. То есть любые подобные ограничения должны быть регламентированы нормами гражданского законодательства исходя из следующего основного принципа: ограничение гражданских прав возможно и допустимо только федеральными законами.

Исследование показывает, что в Гражданском кодексе Российской Федерации целесообразно закрепить такие принципы, как: соразмерность вводимых ограничений гражданских прав целям, которые преследуются при их установлении; обязательное общественное обсуждение устанавливаемых ограничений гражданских прав кредиторов и заемщиков.

Обоснованное и правомерное установление пределов, применение ограничений права в сфере потребительского кредитования позволят избежать социальной напряженности в обществе, воспрепятствуют деструктивной активности отдельных кредитных учреждений.

\section{Ссылки:}

1. Palandt O., Ellenberger J. Kommentar zum BGB = Комментарий к Гражданскому уложению. München, 2011.

2. Лауэ К. Банковское вознаграждение за оформление потребительского кредита и ведение потребительского кредитного счета в соответствии с немецким законодательством // Банковское право. 2011. № 4. С. 71-77.

3. Шерин В.В. Отдельные аспекты установления ограничений гражданских прав субъектов имущественного оборота // Вестник МГОСГИ. 2013. № 4 (16). С. 91-96 ; Шугаев Д.В. Ограничения предпринимательской деятельности иностранных лиц по российскому законодательству : дис. ... канд. юрид. наук. М., 2009.

4. Блошенко М.В. Пределы и ограничения права на осуществление предпринимательской деятельности : дис. .... канд. юрид. наук. Краснодар, 2011.

5. Там же. С. 34.

\section{References:}

Bloshenko, MV 2011, Limits and restrictions on the right to conduct entrepreneurial activities, PhD in Law thesis, Krasnodar, (in Russian).

Laue, K 2011, 'Banking fee for registration of a consumer loan and maintenance of a consumer credit account in accordance with German law', Bankovskoye pravo, no. 4, pp. 71-77, (in Russian).

Palandt, O \& Ellenberger, J 2001, Kommentar zum BGB, München, (in German).

Sherin, VV 2013, 'Certain aspects of setting limits on the civil rights of the subjects of property turnover', Vestnik MGOSGI, no. 4 (16), pp. 91-96, (in Russian).

Shugaev, DV 2009, Restrictions on the entrepreneurial activities of foreigners under Russian law, PhD in Law thesis, Moscow, (in Russian). 